Int. J. Dev. Biol. 55: 603-611

doi: $10.1387 / \mathrm{ijdb} .103254 \mathrm{lh}$

\title{
Expression of the Scavenger Receptor Class B type I (SR-BI) family in Drosophila melanogaster
}

\author{
LEIRE HERBOSO, ANATALAMILLO*, CORALIA PÉREZ and ROSA BARRIO* \\ CIC bioGUNE, Bizkaia Technology Park, Derio, Spain
}

\begin{abstract}
In mammals, cholesterol is transformed into steroid hormones in the adrenal gland, the ovaries or the testes. The Scavenger Receptors Class B Type I (SR-BI) are membrane proteins that belong to the CD36 family and participate in the selective uptake of high density lipoprotein cholesteryl ester in the mammalian steroidogenic tissues. Fourteen members of the CD36 family have been identified in Diptera, although their expression patterns remain uncharacterized. Using in situ hybridization we have characterized the expression patterns of the fourteen SR-Bls in Drosophila melanogaster. We analyzed three different developmental larval stages prior to and during the peak of the insect steroid hormone ecdysone, which triggers the larval to pupal transition. We focused on the steroidogenic tissues, such as the prothoracic gland, the ovaries and the testes, and extended our analysis to non-steroidogenic tissues, such as the fat body, salivary glands, the gut, the gastric caeca or the central nervous system. Our results show highly regulated expression patterns, with three genes crq, pes and Snmp being upregulated in steroidogenic tissues at the onset of pupariation when steroidogenesis is crucial. This study underlines the importance of the transport of cholesterol and steroids in the process of ecdysone synthesis.
\end{abstract}

KEY WORDS: Drosophila, scavenger receptor, CD36, ecdysone, steroidogenesis, expression pattern

Steroid hormones regulate a wide variety of developmental and physiological processes in higher organisms. In mammals, these hormones are synthesized from cholesterol in steroidogenic tissues, such as the adrenal gland, ovaries or testes. In these tissues, as well as in the liver, the Scavenger Receptor Class B type I (SR-BI) is one of the receptors that participate in the selective uptake of cholesterol, mainly in the form of High Density Lipoprotein cholesteryl ester (HDL-CE) (Acton et al., 1996). SR-BI together with CD36, CLA1 and LIMPII belong to the Cluster of Differentiation 36 (CD36) family, that contain two-transmembrane domains and they are often referred to as fatty acid transporters or Scavenger Receptors.

The surface of the steroidogenic cells are endowed with an intricate microvillar system, specialized on lipoprotein trapping (Azhar et al., 1988; Reaven et al., 1984, 1986, 1988, 1989, 1990). This constitutes the microvillar compartment, and the space created between adjacent microvilli forms the microvillar channels (Reaven et al., 1988, 1989, 1990). SR-BI is able by itself to promote the formation of microvillar channels when over-expressed in insect Sf9 cells (Reaven et al., 2001). These channels can trap HDL particles and initiate massive selective uptake of cholesteryl esters. Furthermore, SR-BI is necessary for the formation of the microvillar channels of the adrenal gland, which are disorganized in Srb1\% mice (Williams et al., 2002).

In addition, SR-BI can cause changes in the cholesterol and/ or phospholipids composition of microvillar membranes and it is thought to provoke the formation of specific lipid rafts necessary for microvillar channel formation (Connelly et al., 2001; de La Llera-Moya et al., 1999, 2001; Kellner-Weibel et al., 2000). SR$\mathrm{BI}$ also affects the flux of free cholesterol and properties of the plasma membrane. In addition, the expression of SR-BI and the number and complexity of the microvillar compartment increases in adrenal glands of rats treated with Adeno-Corticotropic Hormone (Azhar et al., 2002), illustrating the relationship between SR-BI expression and the structural configuration of the surface of steroidogenic cells.

Twelve to fourteen CD36 homologues have been identified

\footnotetext{
Abbreviations used in this paper: 20E, 20-hydroxyecdysone; AEL, after egg laying; CNS, central nervous system; crq, croquemort; emp, epithelial membrane protein; HDL-CE, high density lipoprotein cholesteryl ester; L3, third instar larvae; ninaD, neither inactivation nor after-potential D; pes, peste; $\mathrm{PG}$, prothoracic gland; $\mathrm{PTTH}$, prothoracicotropic hormone; santa-maria, scavenger receptor acting in neural tissue and majority of rhodopsin is absent; SR-BI, Scavenger Receptor Class B type I.
}

\footnotetext{
*Address correspondence to: Rosa Barrio or AnaTalamillo. CIC bioGUNE, BizkaiaTechnology Park, 48160 Derio, Spain.

E-mail: rbarrio@cicbiogune.es; atalamillo@cicbiogune.es
} 
in the dipterans $D$. melanogaster, $D$. pseudoobscura, Anopheles gambiae and Aedes aegypti (Nichols and Vogt, 2008). In D. melanogaster, the majority of the fourteen CD36 genes identified are uncharacterized. Some of them, such as epithelial membrane protein (emp), croquemort (crq), neither inactivation nor afterpotential D (ninaD), scavenger receptor acting in neural tissue and majority of rhodopsin is absent (santamaria) and peste (pes), have been linked to a variety of functions, including the immune response, cell adhesion, phototransduction and autophagic cell death, among others. However, their expression patterns during postembryonic development remain mostly uncharacterized. We are particularly interested in the function of these genes in steroidogenic tissues, such as the Prothoracic Gland (PG) (Gilbert et al., 2002), the ovaries and testes, where the implication of these receptors on the cholesterol intake for steroids synthesis remains to be demonstrated. To approach this question, it is necessary to investigate the expression patterns of these genes, paying special attention to the steroidogenic tissues and to one developmental window when high

levels of ecdysteroids are required: the onset of pupa formation.

Here we report the expression patterns of the fourteen CD36 $D$. melanogastergenes in various tissues in three developmental stages close to the moment of pupariation. Our results show that these genes are highly regulated temporally and spatially. Furthermore, some of them are upregulated at the end of the third instar larvae stage (L3), suggesting specific functions in steroidogenic tissues.

\section{Results}

To analyze the expression of the fourteen SR-BI genes, we performed in situ hybridizations in D. melanogaster L3 instar larvae. We analyzed three developmental stages, which we differentiated with the help of food containing bromophenol blue. At $96 \mathrm{~h}$ after egg laying (AEL), larvae are in the third instar and spend most of their time eating; therefore they rarely leave the food from where they were collected. At $120 \mathrm{~h}$ AEL, larvae abandon the food although their gut still contains the blue colorant. Later, the larvae empty their gut, synthesize high levels of ecdysone and will enter into pupariation. We selected these as 120 h AEL clear-gut larvae and corroborated that already received the ecdysone pulse after dissection according to the morphology of their salivary glands (Mitchell et al., 1977). We focused our analysis in the steroidogenic tissues such as PG, ovaries and testes. We analyzed also tissues involved in metabolism, some of them involved in the conversion of
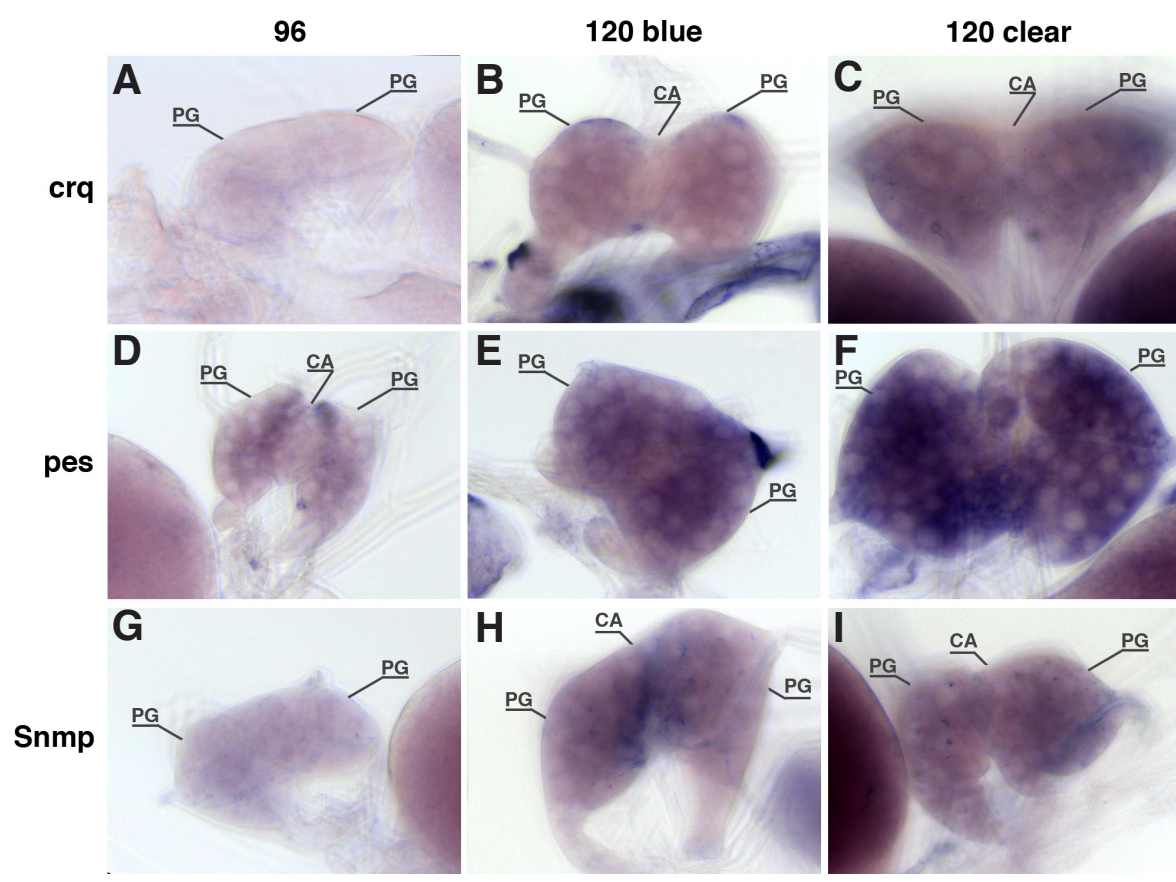

Fig. 1.Temporal regulation of the expression of SR-Bls in the ring gland. Expression of crq (A-C), pes (D-F) and Snmp (G-I) in the ring glands of $96 \mathrm{~h} \mathrm{AEL} \mathrm{larvae} \mathrm{(A,D,G),} 120 \mathrm{~h}$ AEL blue-gut larvae (B,E,H) or 120 h AEL clear-gut larvae (C, F, I). crq, pes and Snmp expression increased with time.

ecdysone to 20-hydroxyecdysone (20E) such as the fat body, midgut and Malpighian tubules and other tissues such as the central nervous system (CNS), salivary gland and gastric caeca. As controls, we did in situ hybridizations using the sense RNA for each gene (data not shown).
96
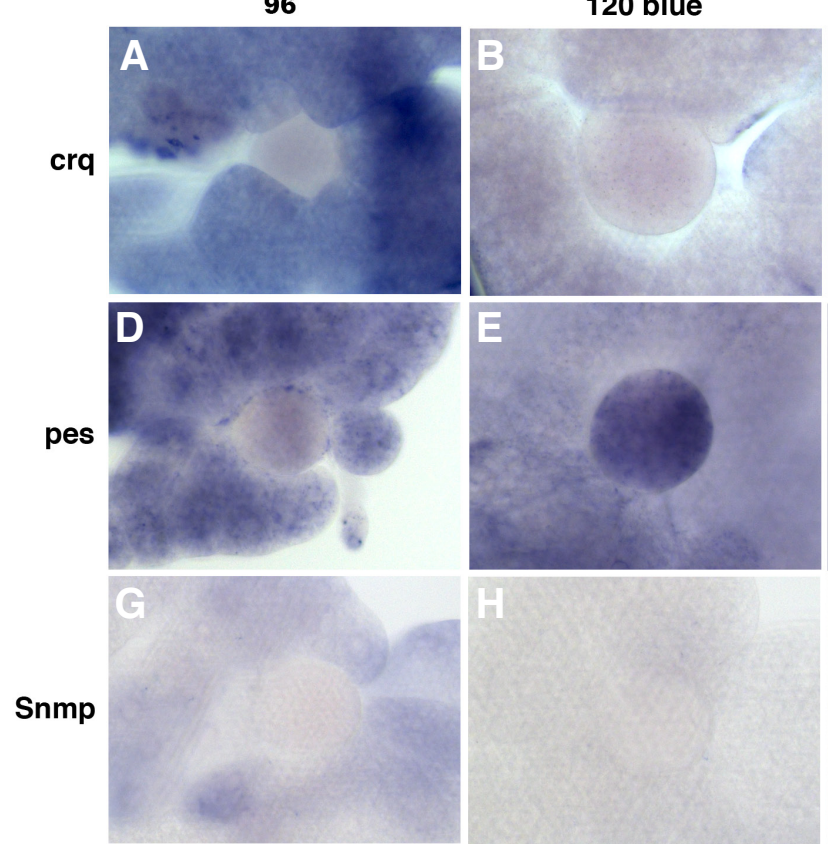

Fig. 2. Temporal regulation of the expression of the SR-Bls in the ovaries. Expression cra (A-C), pes (D-F) and Snmp (G-I) in the ovaries of $96 \mathrm{~h}$ AEL larvae (A,D,G), $120 \mathrm{~h}$ AEL blue-gut larvae (B,E,H) and $120 \mathrm{~h}$ AEL clear-gut larvae (C,F,I). In all cases, the expression is upregulated in $120 \mathrm{~h}$ clear-gut larvae, being restricted to either the anterior or posterior parts of these ovaries. 
TABLE 1

TEMPLATES USED TO SYNTHESIZE THE RNA PROBES

\begin{tabular}{ll} 
Gene & Template \\
\hline CG10345 & GH08773 \\
CG1887 & IP12356 \\
CG2736 & GH15894 \\
CG31741 & PCR product \\
CG3829 & GH19047 \\
CG40006 & RE68569 \\
CG7227 & GH07959 \\
CG7422 & IP10059 \\
crq & RE02070 \\
emp & RE08130 \\
ninaD & RE41741 \\
pes & RE21078 \\
santa-maria & GH23019 \\
Snmp & IP13851 \\
\hline
\end{tabular}

\section{Expression of SR-Bls in steroidogenic tissues}

\section{Ring gland}

The ring gland is a specialized structure in Diptera that contains both ecdysone secreting (PG) and juvenile hormone secreting (corpus allatum) cells, as well as the corpus cardiacum. It is connected to certain neurons in the CNS, constituting the hormonal regulatory organs equivalent to the hypothalamic-pituitary-adrenal axis in vertebrales. We detected expression in the ring gland of three SR-BIs: crq, pes and Snmp (Fig. 1; Table 2). These are upregulated during development, with pes being the only one present at $96 \mathrm{~h} \mathrm{AEL}$. crq and Snmp seem to be restricted to the PG, while a subtle expression of pes can also be detected in the corpus allatum.

\section{Ovaries and Testes}

The gonads are part of the reproductive organs and contain the gametes. Fig. 2 and Fig. 3 show the patterns of all the SR-Bls expressed in ovaries or testes. crq, pes and Snmp are the only SR-Bls expressed in ovaries (Fig. 2; Table 2). crq and Snmp are

TABLE 2

EXPRESSION PROFILE OF THE FOURTEEN D. MELANOGASTER SR-BI GENES AT THREE DEVELOPMENTAL TIMES IN THE INDICATED TISSUES

\begin{tabular}{|c|c|c|c|c|c|c|c|c|c|c|c|c|c|}
\hline & & \multirow[b]{2}{*}{ RG } & \multirow[b]{2}{*}{ FB } & \multicolumn{2}{|c|}{ Gonads } & \multicolumn{5}{|c|}{ Alimentary tract } & \multirow[b]{2}{*}{$\begin{array}{l}\text { Anterior } \\
\text { spiracles }\end{array}$} & \multirow[b]{2}{*}{ SG } & \multirow[b]{2}{*}{ CNS } \\
\hline & & & & Ovary & Testis & $\begin{array}{l}\text { Gastric } \\
\text { caeca }\end{array}$ & Midgut & Hindgut & $\begin{array}{c}\text { Malpighian } \\
\text { tubules }\end{array}$ & $\begin{array}{c}\text { Garland } \\
\text { cells }\end{array}$ & & & \\
\hline CG10345 & $\begin{array}{l}120 \text { clear } \\
120 \text { blue }\end{array}$ & 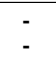 & 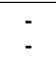 & : & $\begin{array}{c}+++ \\
++\end{array}$ & 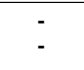 & - & $:$ & $:$ & $+^{1}$ & $\begin{array}{l}- \\
++\end{array}$ & $\overline{-2}$ & - \\
\hline CG1887 & $\begin{array}{c}96 \\
120 \text { clear }\end{array}$ & - & -5 & - & $\begin{array}{c}+ \\
++\end{array}$ & - & - & - & - & $\begin{array}{l}-1 \\
++\end{array}$ & + & $\begin{array}{c}- \\
t^{2}\end{array}$ & $\begin{array}{l}- \\
++\end{array}$ \\
\hline & $\begin{array}{c}120 \text { blue } \\
96\end{array}$ & 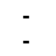 & $+t^{2}$ & : & $\stackrel{++}{+}$ & : & $\check{2}^{2}$ & $:$ & : & $\begin{array}{l}+ \\
++\end{array}$ & $\begin{array}{l}++ \\
+++\end{array}$ & $t_{-2}^{2}$ & $\stackrel{+++}{+}$ \\
\hline CG2736 & $\begin{array}{l}120 \text { clear } \\
120 \text { blue } \\
96\end{array}$ & $:$ & $\begin{array}{c}- \\
++^{2} \\
+++^{2}\end{array}$ & : & $:$ & : & : & $:$ & - & $\begin{array}{l}++ \\
++\end{array}$ & - & : & : \\
\hline CG31741 & $\begin{array}{c}120 \text { clear } \\
120 \text { blue } \\
96\end{array}$ & $:$ & $:$ & $:$ & $:$ & $:$ & $\dot{t}^{2}$ & $:$ & $:$ & $\begin{array}{l}++ \\
++ \\
++\end{array}$ & $:$ & \pm & $:$ \\
\hline CG3829 & $\begin{array}{c}120 \text { clear } \\
120 \text { blue } \\
96\end{array}$ & $:$ & $\begin{array}{c}+++^{2} \\
++^{2} \\
+\end{array}$ & : & $\begin{array}{c}+++ \\
++ \\
+\end{array}$ & $\begin{array}{l}++^{2} \\
+^{2} \\
-\end{array}$ & $\begin{array}{l}++_{2}^{2} \\
+^{2} \\
-\end{array}$ & : & ++ & + & : & $\pm^{2}$ & $:$ \\
\hline CG40006 & $\begin{array}{c}120 \text { clear } \\
120 \text { blue } \\
96\end{array}$ & $:$ & $:$ & $:$ & $\therefore$ & : & $:$ & $:$ & $:$ & \pm & $:$ & \pm & $:$ \\
\hline CG7227 & $\begin{array}{c}120 \text { clear } \\
120 \text { blue } \\
96\end{array}$ & $:$ & \pm & $:$ & $\begin{array}{c}+++ \\
++ \\
+\end{array}$ & 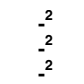 & $\begin{array}{l}+^{2} \\
-2,1 \\
-2\end{array}$ & $:$ & $:$ & $\begin{array}{l}+1 \\
+ \\
+\end{array}$ & $:$ & $\begin{array}{l}.^{2} \\
t^{2}\end{array}$ & $:$ \\
\hline CG7422 & $\begin{array}{c}120 \text { clear } \\
120 \text { blue } \\
96\end{array}$ & $:$ & $:$ & : & $\begin{array}{l}+ \\
++ \\
++\end{array}$ & $\bar{z}^{2}$ & $\begin{array}{l}._{2}^{2} \\
.2\end{array}$ & : & : & $\begin{array}{l}-1 \\
-1 \\
-1\end{array}$ & $\begin{array}{l}- \\
++ \\
++\end{array}$ & $\begin{array}{l}-^{2} \\
.^{2}\end{array}$ & $:$ \\
\hline crq & $\begin{array}{l}120 \text { clear } \\
120 \text { blue } \\
96\end{array}$ & $\begin{array}{l}++ \\
+\end{array}$ & : & \pm & $\begin{array}{l}++ \\
+ \\
+\end{array}$ & $\stackrel{++}{+}$ & $\begin{array}{c}+++ \\
++ \\
+\end{array}$ & : & : & $\begin{array}{l}+ \\
+ \\
+\end{array}$ & $:$ & $\begin{array}{l}t^{2} \\
+\end{array}$ & \pm \\
\hline emp & $\begin{array}{c}120 \text { clear } \\
120 \text { blue } \\
96\end{array}$ & $:$ & : & : & $\begin{array}{l}+++ \\
+++ \\
+++\end{array}$ & : & : & : & 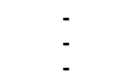 & $:$ & $\begin{array}{l}+++ \\
+++ \\
+++\end{array}$ & $:$ & $:$ \\
\hline $\operatorname{nin} a D$ & $\begin{array}{c}120 \text { clear } \\
120 \text { blue } \\
96\end{array}$ & $:$ & $\begin{array}{c}- \\
+ \\
++^{3}\end{array}$ & $:$ & $:$ & $:$ & $\begin{array}{c}- \\
+++ \\
+++\end{array}$ & $:$ & $\begin{array}{l}-3 \\
+^{3} \\
+^{3}\end{array}$ & $\begin{array}{l}++ \\
++ \\
++\end{array}$ & 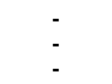 & $:$ & $:$ \\
\hline pes & $\begin{array}{c}120 \text { clear } \\
120 \text { blue } \\
96\end{array}$ & $\begin{array}{c}+++ \\
++ \\
+\end{array}$ & $\begin{array}{c}+++ \\
++ \\
+\end{array}$ & $\begin{array}{c}+++ \\
+\end{array}$ & $\begin{array}{l}+++ \\
+++ \\
+++\end{array}$ & $\begin{array}{l}+++ \\
+++ \\
+++\end{array}$ & $\begin{array}{c}++ \\
+++^{2} \\
+++^{2}\end{array}$ & $\begin{array}{l}++ \\
++ \\
++\end{array}$ & $\begin{array}{l}++ \\
++ \\
++\end{array}$ & $\begin{array}{l}++ \\
++ \\
++\end{array}$ & $\begin{array}{c}+++ \\
++ \\
+\end{array}$ & $\begin{array}{l}++++^{2} \\
+++^{2} \\
+++\end{array}$ & $\begin{array}{c}+++ \\
++ \\
+\end{array}$ \\
\hline santa-maria & $\begin{array}{c}120 \text { clear } \\
120 \text { blue } \\
96\end{array}$ & $:$ & $\begin{array}{c}+++ \\
-\end{array}$ & $:$ & $:$ & : & $\begin{array}{l}++_{2}^{2} \\
-2 \\
2^{2}\end{array}$ & $:$ & $:$ & + & $:$ & $:$ & $\begin{array}{c}+++ \\
++ \\
+\end{array}$ \\
\hline Snmp & $\begin{array}{c}120 \text { clear } \\
120 \text { blue } \\
96\end{array}$ & $\begin{array}{l}++ \\
++\end{array}$ & $\dot{t}^{3}$ & \pm & $\begin{array}{l}+++ \\
++ \\
++\end{array}$ & : & $:$ & : & : & $\begin{array}{l}+ \\
+ \\
+\end{array}$ & : & $\begin{array}{c}+^{2} \\
++^{2} \\
2_{-2}^{2}\end{array}$ & \pm \\
\hline
\end{tabular}


only expressed in $120 \mathrm{~h}$ clear-gut larvae, while the expression of pes became apparent in $120 \mathrm{~h}$ blue-gut larvae and increased close to the moment of pupariation. The spatial expression of the three SR-Bls is restricted to one pole of the ovary, especially evident for pes.

Nine of the SR-Bls are expressed in the testes: CG10345, CG1887, CG3829, CG7227, CG7422, crq, emp, pes, and Snmp (Fig. 3; Table 2). Some genes, like CG7227, pes, or Snmp are expressed throughout the testis, while some others are restricted to the anterior (crq), the posterior (CG10345) or the central parts (CG1887, CG3829 or CG7422). empextended its expression from the posterior part to the whole testis. With respect to the temporal regulation, the patterns are highly variable, with expression being constant for pes, upregulated for CG10345, CG1887, CG3829, CG7227, crqand Snmp or downregulated for CG7422.

\section{Expression of SR-Bls in other tissues}

\section{Fat body}

The fat body is the main energy storage tissue of the organism and is also implicated in the immune response by the production of antimicrobial peptides and in the conversion of ecdysone to 20E. Ecdysone 20-monooxygenase, the enzyme that hidroxylates ecdysone to $20 \mathrm{E}$, is also present in other tissues peripheral to the PG such as the Malpighian tubules and the midgut (Petryk et al., 2003). Fig. 4 shows the eight SR-Bls expressed in the fat body: CG1887, CG2736, CG3829, CG7227, ninaD, pes, santa-maria, and Snmp (Table2). ninaDand Snmp show a heterogeneous pattern at $96 \mathrm{~h} \mathrm{AEL} \mathrm{and}$ $120 \mathrm{~h}$ blue-gut, respectively, some cells showing higher expression than others (Fig. $4 \mathrm{M}, \mathrm{W}$ ). The expression of some of these genes follows a temporal regulation. CG3829 and pes are upregulated throughout development, while CG2736 and ninaD are downregulated. CG1887 is upregulated in $120 \mathrm{~h}$ blue-gut larvae and downregulated in $120 \mathrm{~h}$ clear-gut larvae. santa-maria is only expressed in $120 \mathrm{~h}$ clear-gut larvae and CG7227 in $120 \mathrm{~h}$ blue-gut larvae.

\section{Alimentary tract}

The alimentary tract includes the proventriculus, the gastric caeca, the garland cells, the midgut, the hindgut and the Malpighian tubules. The gut and the gastric caeca are the principal organs involved in the secretion of digestive enzymes and the digestion and absorption of the food. The gut plays also an important role in the immune response. The Malpighian tubules, joined to the alimentary tract at the junction between the midgut

Fig. 3. Temporal regulation of the expression of the SRBIs in the testes. Expression of CG10345 (A-C), CG1887 (D-F), CG3829 (G-I), CG7227 (J-L), CG7422 (M-O), crq (P-R), emp (S-U), pes (V-X) and Snmp (Y-AA) in the testes of 96 h AEL larvae (A,D, G,J,M,P,S,V,Y), 120 h AEL blue-gut larvae $(\mathbf{B}, \mathbf{E}, \mathbf{H}, \mathbf{K}, \mathbf{N}, \mathbf{Q}, \mathbf{T}, \mathbf{W}, \mathbf{Z})$ or $120 \mathrm{~h}$ AEL clear-gut larvae $(\mathbf{C}, \mathbf{F}, \mathbf{I}, \mathbf{L}, \mathbf{O}, \mathbf{R}, \mathbf{U}, \mathbf{X}, \mathbf{A A})$. Anterior is to the left.

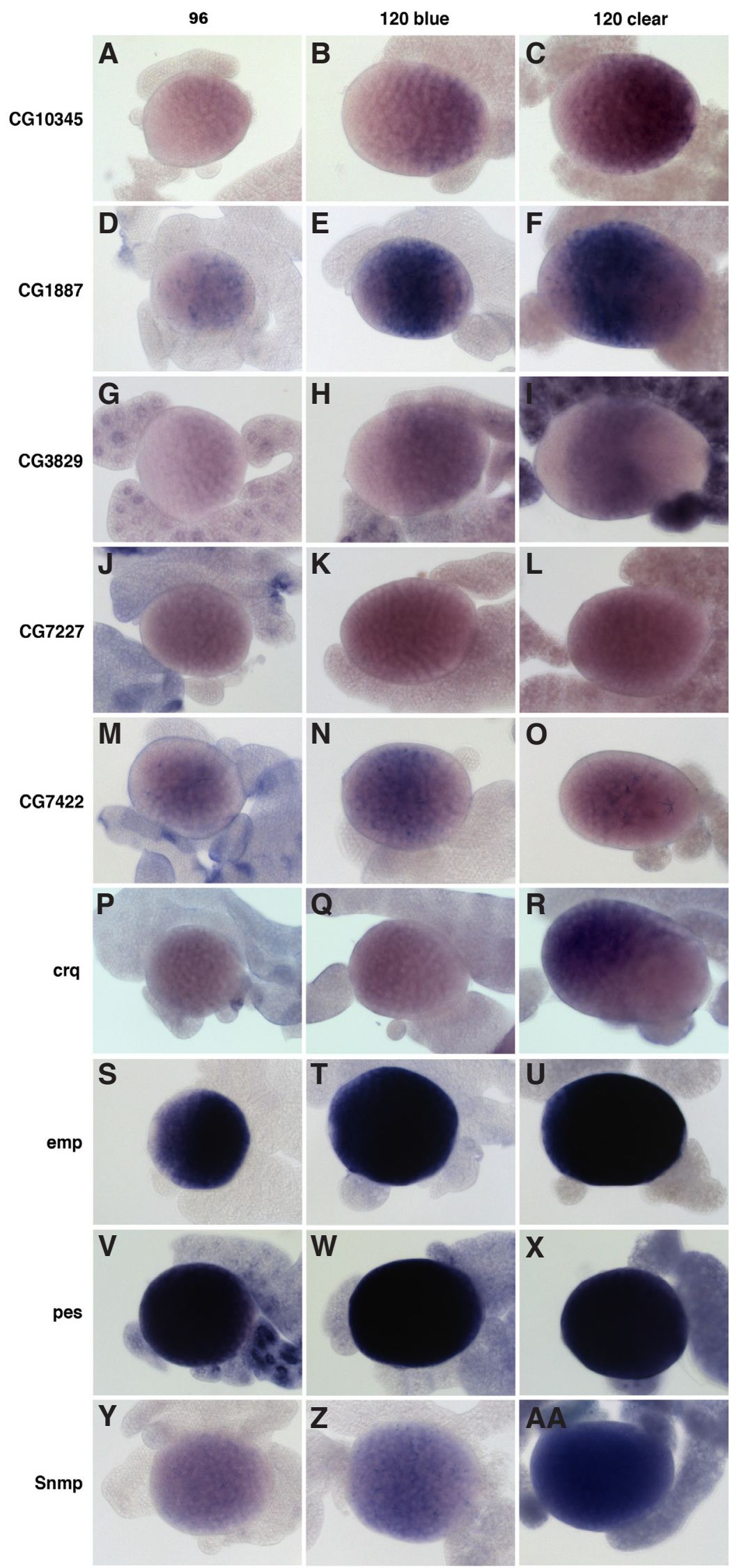


and hindgut, perform excretory and osmoregulatory functions. In Drosophila the contribution of midgut and Malpighian tubules in steroidogenesis may be less significant than the fat body. Little is known about the function of the garland cells, although they are considered to be athrocytes, cells that uptake material from the hemolymph and are highly active in clathrin-mediated endocytosis. Twelve out of the fourteen SR-Bls are expressed in at least one of the components of the alimentary tract, with pes being the most ubiquitous (Table 2).

CG3829, crq and pes are expressed in the gastric caeca (Table 2). CG3829 and crq are upregulated during development, while pesexpression is constant. crq shows a heterogeneous pattern, with the level of expression differing among cells (Fig. 5 A-C).

Seven of the SR-BIs are expressed in the midgut: CG31741, CG3829, CG7227, crq, ninaD, pesand santa-maria (Table 2). The expression of CG3829, CG7227, crq and santa-maria increased during development, while the expression of nina $D$ and pes decreased. At 96 h AEL ninaD is expressed throughout the midgut with the exception of the most anterior portion. This pattern is broader in blue-gut larvae at $120 \mathrm{~h}$, with the limit of the expression being shifted anteriorly, and is downregulated in the entire gut just before pupariation (Table 2 and Fig. 5 G-I). By contrast, pes is the only SR-BI expressed in the hindgut, with no evidence of temporal regulation.

CG3829, ninaD and pes are expressed in the Malpighian tubules (Table 2). pes expression is constant during development while CG3829 is upregulated and ninaDis downregulated with time. The expression of nina $D$ is restricted to a few cells localized in the part in closer proximity to the gut (Fig. 5 D-F).

CG10345, CG1887, CG2736, CG31741, CG3829, CG40006, CG7227, crq, ninaD, pes, santa-mariaand Snmpare expressed in the garland cells (Table 2). CG10345, CG3829, CG40006, crq and santa-maria expression is upregulated during development, while CG2736, CG31741, CG7227, ninaD, pes and Snmp expression is not temporally regulated.

\section{Anterior spiracles}

The spiracles are the external tracheal apertures, which contain spiracular glands that produce lipids secretions. These coat the surface of the spiracular plate and branched hairs (Keilin, 1944; Keilin etal., 1935; Rizki, 1956). CG10345, CG1887, CG7422, emp and pes are expressed in this organ (Table 2). CG10345, CG1887 and CG7422 are downregulated throughout development, while pes is upregulated and emp remains constant. The expression patterns of these genes show spatial restrictions. CG10345, CG1887, CG7422and emp are expressed at some developmental times in the
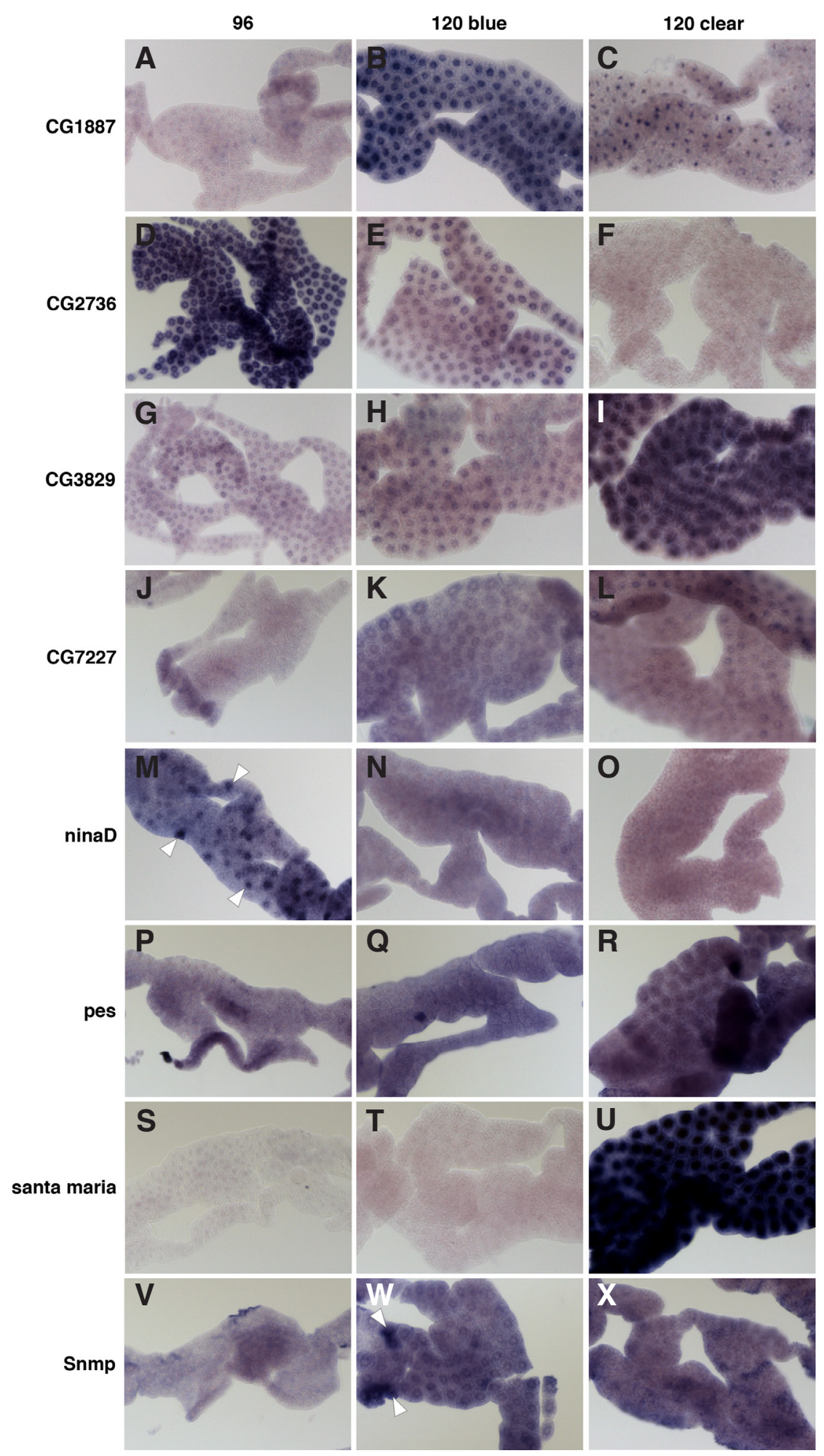

Fig. 4. Temporal regulation of the expression of the SR-Bls in the fat body. Expression of CG1887 (A-C), CG2736 (D-F), CG3829 (G-I), CG7227 (J-L), ninaD (M-O), pes (P-R), santa maria (S-U) and Snmp CG31741 (V-X) in the fat body of 96 h AEL larvae (A,D,G,J,M,P,S, V),

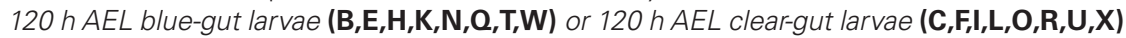
Arrowheads in $\mathbf{( M , W )}$ indicate cells with higher expression than the others. 
cells of the gland closer to the spiracular plate, while pes is expressed throughout the gland (Fig. $5 \mathrm{~J}-\mathrm{O}$ ).

\section{Salivary gland}

The salivary glands are accessory organs for digestion. When the larvae are going to enter into pupariation, salivary glands secrete the glue proteins, which allow the larvae to stick to a surface until the adult emerges from the pupal case. Eight SR-Bls are expressed in the salivary gland: CG1887, CG31741, CG3829, CG40006, CG7227, crq, pes and Snmp. Among those, pes is the only one highly expressed throughout the three developmental times analyzed, while the others are temporally regulated (Table 2 ).

\section{Central nervous system}

CG1887, crq, pes, santa-maria, and Snmp are expressed in the CNS (Table 2). crq, pes, santa-maria and Snmp are upregulated during development, while CG1887 shows higher expression in $120 \mathrm{~h}$ blue-gut larvae. These genes show spatially restricted patterns. CG1887, crq and pes are expressed in the brain hemispheres and the more anterior part of the ventral ganglion. Snmp expression is restricted to the brain hemispheres. Expression of santa-mariaappeared in the brain hemispheres of $96 \mathrm{~h}$ larvae, but in $120 \mathrm{~h}$ clear-gut larvae the expression became ubiquitous (Fig. 5 P-U).

\section{Discussion}

The CD36/SR-BI gene family in mammals is composed by four members, CD36, CLA1, LIMPII and SR-BI, which show a broad range of functions and widespread expression patterns; CD36 is expressed in blood cells, adipocytes,

Fig. 5.Temporal regulation of the SR-BIs in non esteroidogenic tissues. Non-homogeneous expression of $\mathrm{crq}$ (A-C) in gastric caeca (GC), arroheads indicate cells whit a higher level of expression, (Pv: proventiculus, MG: midgut, G: garland cells). Restricted expression of ninaD (D-F) to a few cells (arrowheads) of the Malphigina tubules (MT) and (G-I) shows the particular expression pattern in the $M G$, arrows indicate the point where the expression stars. Expression in the anterior spiracles of pes (J-L) in the whole spiracular gland (indicated by brace) and CG10345 (M-O) in specific cells of the gland (arrowheads). Expression of santa-maria (P-R) and CG1887 (S-U) in the CNS (RG: ring-gland, BH: brain hemispheres, VG: ventralganglio). Expression of santa-maria (V-X) in eye-antennal imaginal disc, arrowheads indicate the photoreceptor cluster (A: antennal segment, ED: eye disc). Expression of emp (Y-AA) in tracheas (T). (A,D, G, J,M $\mathbf{M}, \mathbf{P}, \mathbf{S}, \mathbf{V}, \mathbf{Y})$ correspond to $96 \mathrm{~h}$ AEL larvae, $(\mathbf{B}, \mathbf{E}, \mathbf{H}, \mathbf{K}, \mathbf{N}, \mathbf{Q}, \mathbf{T}, \mathbf{W}, \mathbf{Z})$ to $120 \mathrm{~h} A E L$ blue-gut larvae and (C,F,I,L,O,R,U,X,AA) to $120 \mathrm{~h}$ AEL clear-gut larvae. Anterior is to the left.

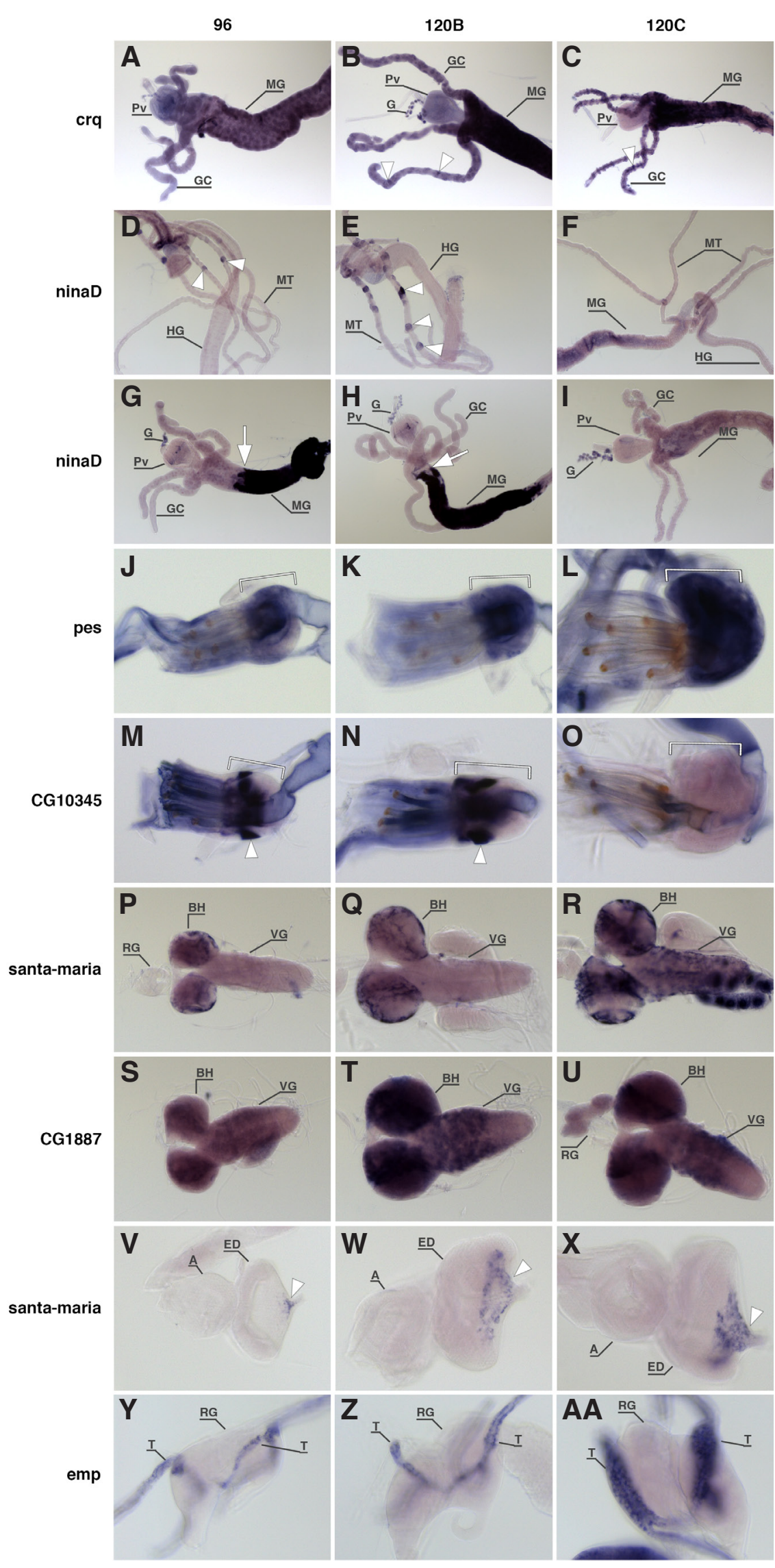


endothelial cells and retinal and mammary epithelia. There, CD36 is implicated in cell adhesion, phagocytosis of apoptotic cells and signal transduction, as well as in transport and absorption of lipoproteins and fatty acids (Abumrad et al., 1993; Greenwalt et al., 1992; Oquendo et al., 1989; Ryeom et al., 1996); CLA1 is expressed in the adrenal gland, liver, testes, monocytes and macrophages. It binds to apoptotic thymocytes and acts as a lipoprotein receptor (Calvo and Vega, 1993; Murao et al., 1997; Pussinen et al., 2000); LIMPII localizes in lysosomal membranes and it is implicated in cell adhesion (Vega et al., 1991); SR-BI is located in fat, lung, liver, ovary and adrenal gland, being also a lipoprotein receptor (Acton et al., 1994; Rigotti et al., 1995).

Multiple orthologues of this family have been identified in invertebrates. In the case of the nematode $C$. elegans, six CD36-like proteins have been identified, which are implicated in the engulfment of apoptotic cell. The expression of this proteins covers many tissues, such as the intestine, the hypodermal cells, and the head and tail of L1 larvae (Hoque and Chalfie, 2001). In insects, twelve to fourteen CD36 genes were identified in dipteran and coleopteran, while eight in hymenopteran. However, little information is available about the SR-Bls from other insect species outside $D$. melanogaster (Nichols and Vogt, 2008). The existence of fourteen homologues of this family could indicate a diversification of functions in arthropods (Nichols and Vogt, 2008). The physiological functions of the $D$. melanogaster members of this family are largely uncharacterized, with the exception of $c r q$, nina $D$, emp, santa-maria and Snmp, which show roles in immunity, absorption of carotenoid or pheromone recognition, among others. Our results suggest a role for some of these genes in steroidogenic tissues. In addition, the expression of some of them in the alimentary tract and in the fat body would suggest a function in the lipid and energy homeostasis of the organism.

In the scope of our study, where we focused our attention on three developmental times in a variety of larval tissues, we could observe highly dynamic and, in some cases, restrictive patterns of expression. Some genes show a broad expression in most of the tissues analyzed, such as pes, while others are more restricted, such as CG40006 or CG2736 (Table 2). It is also remarkable the temporal regulation that some of these genes undergo in a relatively short period of time. For instance, santa-maria shows a strong upregulation in the fat body in clear-gut versus blue-gut larvae (Fig. $4 \mathrm{~T}, \mathrm{U}$ ), while CG2736 is downregulated in the same tissue (Fig. 4 $\mathrm{D}, \mathrm{E})$. nina $\mathrm{D}$ is also visibly downregulated in the midgut during the transition from blue to clear-gut (Fig. $5 \mathrm{H}, \mathrm{I})$. Another example of specificity is the expression of emp in the tracheae (Fig. 5 Y-AA).

In mammals, SR-BI is essential for the formation of microvillar channels and HDL-CE uptake in adrenal gland (Reaven et al., 2001; Williams et al., 2002). We report here the expression of the $D$. melanogasterSR-Bls homologues in tissues in which they could be involved in the capture of cholesterol or other lipids. A previous report showed that nina $D$ is implicated in the absorption of dietary carotenoids, which are lipid soluble tetraterpenoids (Voolstra et al., 2006). Carotenoids are stored in adipose tissues and, in pupal stages, NinaD redistributes the carotenoids from adipose tissue to the developing eyes (Kiefer et al., 2002). The expression of nina $D$ was also described in other larval tissues, such as the CNS, the fat body, the midgut, the hindgut and the Malpighian tubules (Voolstra et al., 2006; Yang and O'Tousa, 2007). Consistent with the literature, our study corroborates the expression of ninaD in the fat body, the midgut and the Malpighian tubules, and reveals its expression in the garland cells. In addition, we also show that the expression of ninaD in the midgut is temporally regulated (Fig. $5 \mathrm{G}-\mathrm{I})$. This highly regulated pattern of expression might indicate a role for ninaD in the uptake of carotenoids or other lipids in the gut prior to pupariation. Another homologue, santa-maria has also been involved in the biosynthesis of rhodopsin, acting in neurons and glia cells, outside the retina (Wang et al., 2007). Recently, a new role for retinoid biosynthesis in regulating the expression of the neuropeptide prothoracicotropic hormone (PTTH) and delaying development in response to tissue damage has been described (Halme et al., 2010). Interestingly, this study suggests that santamaria is partially involved in the delay of the Ptth gene upregulation and, therefore, in the delay of pupariation after damage to imaginal discs. We have observed santa-mariaexpression in the photoreceptor cluster of the eye-antenna imaginal discs, which is upregulated at the stages prior to pupariation. Our results are in concordance with its described function and support the role of these receptors in the process of pupariation (Fig. $5 \mathrm{~V}$-X). santa-maria, as well as CG3829 and emp, is also involved in autophagic cell death of the salivary gland during pupariation (Gorski et al., 2003).

Some of the other SR-Bls also act as phagocytic receptors for apoptotic cells, bacteria and virus, playing important roles in the immune response. For instance, $\mathrm{crq}$ is expressed in $D$. melanogasterhaemocytes/macrophages and it plays a specific role in the recognition and phagocytosis of apoptotic cells and Staphylococcus aureus (Franc et al., 1996, 1999; Sears et al., 2003; Stuart et al., 2005). Its expression is also upregulated after a viral infection (Go et al., 2006). Our results show that $c r q$ is upregulated in the gastric caeca, midgut and garland cells, with these tissues being the primary barrier against the ingested microbes and inhaled fungal spores. pes is required for the uptake of Mycobacterium smegmatis and Listeria monocytogenes by macrophages (Philips et al., 2005), and its expression in midgut and salivary glands has been previously described (Cao et al., 2007; Li et al., 2009). CG2736 appears to be part of the $D$. melanogaster lipid droplet subproteome (Beller et al., 2006), being induced by infection with Octosporea muscaedomesticae (Roxstrom-Lindquist et al., 2004) and upregulated in fly stocks resistant to infection with Pseudomonas aeruginosa, as well as CG10345 (Ye et al., 2009). In the case of Snmp, it is required for pheromone sensitivity in Drosophila and it is implicated in the reception of 11-cis-vaccenyl acetate (cVA), which mediates a variety of behaviours including aggregation, mate recognition and sexual behaviour. cVA is detected by a small set of olfactory neurons located in T1 trichoid sensilla on the antennae of males and females, where Snmp is expressed (Jin et al., 2008).

\section{SR-BIs in steroidogenic tissues}

Ecdysteroid hormones, mainly ecdysone and 20E, have an important role in insect development by controlling molting and metamorphosis. In the majority of the insects, the $P G$ is the major source of ecdysteroids during larval development, the gonads being the primary source of the hormone in the adults as the PG deteriorates. In D. melanogaster, ecdysone synthesis occurs primarily in the PG cells and in the ovary (Gilbert et al., 2002). These tissues require high amounts of cholesterol to synthesize steroid hormones, which are responsible for insect growth and development. However, the receptors involved in cholesterol uptake in the PG remain uncharacterized. In this manuscript, we report 
the identification of three SR-BI homologues expressed in the PG cells, crq, pes and Snmp, all of them being upregulated prior to pupariation, suggesting a possible function for these factors in steroidogenesis that remains to be explored.

Gonadal ecdysteroidogenesis in arthropods was first reported for ovaries of the mosquito Aedes aegypti (Hagedorn et al., 1975) In many other insects the ovary synthesizes and accumulate ecdysteroids in the adults (Romañá et al., 1995; Thompson et al., 1984). In addition, in Gryllus bimaculatus ecdysteroids synthesis by the ovary and abdominal integument in the last instar larvae has been suggested (Gerstenlauer and Hoffmann, 1995). Larval testes are also able to synthesized ecdysteroids and release them, as demonstrated from the inner testicular sheat of Heliothis virescens (Loeb, 1986; Loeb et al., 1982). It is interesting to note that crq, pes and Snmp are expressed in the larval ovaries and at least $c r q$ is expressed in adult ovaries as well (data not shown). These three genes are also expressed in testes. pes shows strong expression throughout the testis in all the three stages, while crq is restricted to the anterior part of the testis where the spermatogonia are localized and it is upregulated during development, suggesting the possibility that crq plays a role in the differentiation of these cells. The expression of Snmp in fat body and in ovary and testis is also temporally regulated, which could indicate a function for this gene in the steroidogenic tissues prior to pupariation. In contrast to the $P G$ and the ovaries, where only these three genes are expressed at these stages, six other genes show expression in the testes, which could indicate a wider diversity of functions in this tissue.

In summary, we show here the expression of scavenger receptor homologues in $D$. melanogaster in a variety of tissues during the third instar larvae. Of particular interest is the regulation of the expression from feeding larvae to wandering larvae and the transition from blue-gut to clear-gut larvae. Our results show that crq, pes and Snmp are interesting candidates to be analyzed in the process of steroidogenesis during the larval to pupal transition.

\section{Materials and Methods}

\section{Drosophila melanogaster larvae collection}

Vallecas was used as wild type strain. Flies were let to lay eggs for 8 $\mathrm{h}$ at $25^{\circ} \mathrm{C}$ on tubes with food containing bromophenol blue at $0.05 \%(\mathrm{w} / \mathrm{v})$ (Maroni and Stamey, 1983). Larvae were collected at three developmental moments: $96 \mathrm{~h} \mathrm{AEL}, 120 \mathrm{~h} \mathrm{AEL}$ with blue dye remaining in the gut and 120 $\mathrm{h} A E L$ larvae that already cleared their gut. The majority of larvae with dark blue gut will pupariate in 12-24 $\mathrm{h}$; the larvae with partially cleared gut will pupariate in 5-12 h, and most of the clear gut larvae will pupariate in 1-6 h (Andres and Thummel, 1994).

\section{RNA probe preparation and in situ hybridization}

ESTs from the Berkeley Drosophila Genome Project cDNA collections or PCR product were used as templates for the synthesis of the RNA probes (Table 1). In the case of CG31741, genomic DNA was amplified using the primers CG31741-179Fw (5'-TTTACGACAACACCTTTGGCTGGTT-3') and CG31741-709Rev (5'-TGCCGAGAGTGGGCTCCATTATCAC-3'). The product of amplification was cloned into the TOPO ${ }^{\circledR}$ vector (Invitrogen).

Plasmid DNA was linearized using a restriction enzyme downstream from the cloned insert (BamHI or Xhol, Fermentas). RNA labelling was performed using the DIG RNA labelling Mix (Roche) according to the manufacture instructions, using $1 \mu \mathrm{g}$ of the linearized DNA.

The RNA probes were hybridized to larval tissues at $55^{\circ} \mathrm{C}$ in $50 \%$ deionized formamide (Sigma), $5 \mathrm{x}$ saline sodium citrate, $50 \mu \mathrm{g} / \mathrm{ml}$ heparin sodium salt (Sigma), $0.1 \%$ Tween 20 , and $100 \mu \mathrm{g} / \mathrm{ml}$ of phenol extracted sonicated salmon sperm DNA (Amersham Biosciences). Samples were incubated with anti-digoxigenin antibody (1:2000; AP Fab fragments, Roche) and signal was detected using 4-Nitro blue tetrazolium chloride and 5-Bromo-4-chloro-3-indolyl-phosphate (Roche). DAPI staining was used to determine the anterior/posterior ends of the larval testis.

\section{Microscopy}

A Zeiss Axio Imager.A1 microscope, coupled to a Zeiss AxioCam HRC photo camera, and a Zeiss Axio Imager.D1, coupled to a Zeiss AxioCam $\mathrm{HRm}$, were used and the AxioVision AC (release 4.8) software. Pictures were processed using the Adobe Photoshop software.

\section{Acknowledgements}

We thank J. D. Sutherland for the critical reading of the manuscript. We also thank the Spanish MICINN (BFU2008-01884 and the Consolider Program CSD2007-008-25120), the Departments of Education and Industry of the Basque Government (PI2009-16 and Etortek Research Programs 2008/2009) and the Bizkaia County. LH is recipient of a FPI fellowship from the Spanish MICINN.

\section{References}

ABUMRAD, N.A., EL-MAGHRABI, M.R., AMRI, E.Z., LOPEZ, E. and GRIMALDI, P.A. (1993). Cloning of a rat adipocyte membrane protein implicated in binding or transport of long-chain fatty acids that is induced during preadipocyte differentiation. Homology with human CD36. J Biol Chem 268: 17665-17668.

ACTON, S., RIGOTTI, A., LANDSCHULZ, K.T., XU, S., HOBBS, H.H. and KRIEGER, M. (1996). Identification of scavenger receptor SR-BI as a high density lipoprotein receptor. Science 271: $518-520$

ACTON, S.L., SCHERER, P.E., LODISH, H.F. and KRIEGER, M. (1994). Expression cloning of SR-BI, a CD36-related class B scavenger receptor. J Biol Chem 269: 21003-21009.

ANDRES, A.J. and THUMMEL, C.S. (1994). Methods for quantitative analysis of transcription in larvae and prepupae. Methods Cell Biol 44: 565-573.

AZHAR, S., COOPER, A., TSAI, L., MAFFE, W. and REAVEN, E. (1988). Characterization of apoB, E receptor function in the luteinized ovary. J Lipid Res 29: 869-882.

AZHAR, S., NOMOTO, A. and REAVEN, E. (2002). Hormonal regulation of adrenal microvillar channel formation. J Lipid Res 43: 861-871.

BELLER, M., RIEDEL, D., JANSCH, L., DIETERICH, G., WEHLAND, J., JACKLE, H. and KUHNLEIN, R.P. (2006). Characterization of the Drosophila lipid droplet subproteome. Mol Cell Proteomics 5: 1082-1094.

CALVO, D. and VEGA, M.A. (1993). Identification, primary structure, and distribution of CLA-1, a novel member of the CD36/LIMPII gene family. J Biol Chem 268: 18929-18935.

CAO, C., LIU, Y. and LEHMANN, M. (2007). Fork head controls the timing and tissue selectivity of steroid-induced developmental cell death. J Cell Biol 176: 843-852.

CONNELLY, M.A., DE LA LLERA-MOYA, M., MONZO, P., YANCEY, P.G., DRAZUL, D., STOUDT, G., FOURNIER, N., KLEIN, S.M., ROTHBLAT, G.H. and WILLIAMS D.L. (2001). Analysis of chimeric receptors shows that multiple distinct functional activities of scavenger receptor, class $B$, type I (SR-BI), are localized to the extracellular receptor domain. Biochemistry 40: 5249-5259.

DE LA LLERA-MOYA, M., CONNELLY, M.A., DRAZUL, D., KLEIN, S.M., FAVARI E., YANCEY, P.G., WILLIAMS, D.L. and ROTHBLAT, G.H. (2001). Scavenger receptor class $B$ type I affects cholesterol homeostasis by magnifying cholestero flux between cells and HDL. J Lipid Res 42: 1969-1978.

DE LA LLERA-MOYA, M., ROTHBLAT, G.H., CONNELLY, M.A., KELLNER-WEIBEL, G., SAKR, S.W., PHILLIPS, M.C. and WILLIAMS, D.L. (1999). Scavenger receptor $\mathrm{BI}$ (SR-BI) mediates free cholesterol flux independently of HDL tethering to the cell surface. J Lipid Res 40: 575-580.

FRANC, N.C., DIMARCQ, J.L., LAGUEUX, M., HOFFMANN, J. and EZEKOWITZ, R.A. (1996). Croquemort, a novel Drosophila hemocyte/macrophage receptor that recognizes apoptotic cells. Immunity 4: 431-443.

FRANC, N.C., HEITZLER, P., EZEKOWITZ, R.A. and WHITE, K. (1999). Requirement for croquemort in phagocytosis of apoptotic cells in Drosophila. Science 284: 1991-1994.

GERSTENLAUER, B. and HOFFMANN, K.H. (1995). Ecdysteroid release and 
ecdysteroid titer during larval-adult development of the Mediterranean field cricket, Gryllus bimaculatus (Ensifera, Gryllidae). Eur. J. Entomology 91: 81-82.

GILBERT, L.I., RYBCZYNSKI, R. and WARREN, J.T. (2002). Control and biochemical nature of the ecdysteroidogenic pathway. Annu Rev Entomol 47: 883-916.

GO, E.P., WIKOFF, W.R., SHEN, Z., O'MAILLE, G., MORITA, H., CONRADS, T.P., NORDSTROM, A., TRAUGER, S.A., URITBOONTHAI, W., LUCAS, D.A. et al., (2006). Mass spectrometry reveals specific and global molecular transformations during viral infection. J Proteome Res 5: 2405-2416.

GORSKI, S.M., CHITTARANJAN, S., PLEASANCE, E.D., FREEMAN, J.D., ANDERSON, C.L., VARHOL, R.J., COUGHLIN, S.M., ZUYDERDUYN, S.D., JONES, S.J. and MARRA, M.A. (2003). A SAGE approach to discovery of genes involved in autophagic cell death. Curr Biol 13: 358-363.

GREENWALT, D.E., LIPSKY, R.H., OCKENHOUSE, C.F., IKEDA, H., TANDON, N.N. and JAMIESON, G.A. (1992). Membrane glycoprotein CD36: a review of its roles in adherence, signal transduction, and transfusion medicine. Blood80: 1105-1115.

HAGEDORN, H.H., O'CONNOR, J.D., FUCHS, M.S., SAGE, B., SCHLAEGER, D.A. and BOHM, M.K. (1975). The ovary as a source of alpha-ecdysone in an adult mosquito. Proc Natl Acad Sci USA 72: 3255-3259.

HALME, A., CHENG, M. and HARIHARAN, I.K. (2010). Retinoids regulate a developmental checkpoint for tissue regeneration in Drosophila. Curr Biol 20: 458-463.

HOQUE, R. and CHALFIE, M. (2001). CD36-like proteins and alpha-integrin are needed for cell death engulfment. International C. elegans Meeting 628 (Abstr.).

JIN, X., HA, T.S. and SMITH, D.P. (2008). SNMP is a signaling component required for pheromone sensitivity in Drosophila. Proc Natl Acad Sci USA 105: 10996-11001.

KEILIN, D. (1944). Respiratory systems and respiratory adaptations in larvae and pupae of Diptera. Parasitology 36.

KEILIN, D., TATE, P. and VINCENT, M. (1935). The perispiracular glands of mosquito larvae. Parasitology 27: 257-262.

KELLNER-WEIBEL, G., DE LA LLERA-MOYA, M., CONNELLY, M.A., STOUDT, G., CHRISTIAN, A.E., HAYNES, M.P., WILLIAMS, D.L. and ROTHBLAT, G.H. (2000) Expression of scavenger receptor $\mathrm{BI}$ in COS-7 cells alters cholesterol content and distribution. Biochemistry 39: 221-229.

KIEFER, C., SUMSER, E., WERNET, M.F. and VON LINTIG, J. (2002). A class B scavenger receptor mediates the cellular uptake of carotenoids in Drosophila. Proc Natl Acad Sci USA 99: 10581-10586.

LI, H.M., SUN, L., MITTAPALLI, O., MUIR, W.M., XIE, J., WU, J., SCHEMERHORN, B.J., SUN, W., PITTENDRIGH, B.R. and MURDOCK, L.L. (2009). Transcriptional signatures in response to wheat germ agglutinin and starvation in Drosophila Melanogaster larval midgut. Insect Mol Biol 18: 21-31.

LOEB, M. (1986). Ecdysteroids in testis sheaths of Heliothis virescens larvae: an immunocytological study. Arch Insect Biochem. Physiol. 3: 173-180.

LOEB, M.J., WOODS, C.W., BRANDT, E.P. and BOAKOVEC, A.B. (1982). Larval testes of the tobacco budworm: a new source of insect ecdysteroids. Science 218: 896-898.

MARONI, G. and STAMEY, S.C. (1983). Use of blue food to select synchronous late third instar larvae. Drosophila Information Service 59: 142-143.

MITCHELL, H.K., TRACY, U.W. and LIPPS, L.S. (1977). The prepupal salivary glands of Drosophila Melanogaster. Biochem Genet 15: 563-573.

MURAO, K., TERPSTRA, V., GREEN, S.R., KONDRATENKO, N., STEINBERG, D. and QUEHENBERGER, O. (1997). Characterization of CLA-1, a human homologue of rodent scavenger receptor $\mathrm{BI}$, as a receptor for high density lipoprotein and apoptotic thymocytes. J Biol Chem 272: 17551-17557.

NICHOLS, Z. and VOGT, R.G. (2008). The SNMP/CD36 gene family in Diptera, Hymenoptera and Coleoptera: Drosophila Melanogaster, D. pseudoobscura, Anopheles gambiae, Aedes aegypti, Apis mellifera, and Tribolium castaneum. Insect Biochem Mol Biol 38: 398-415.

OQUENDO, P., HUNDT, E., LAWLER, J. and SEED, B. (1989). CD36 directly mediates cytoadherence of Plasmodium falciparum parasitized erythrocytes. Cell58:95-101.

PETRYK, A., WARREN, J.T., MARQUES, G., JARCHO, M.P., GILBERT, L.I., KAHLER, J., PARVY, J.P., LI, Y., DAUPHIN-VILLEMANT, C. and O'CONNOR, M.B. (2003). Shade is the DrosophilaP450 enzyme that mediates the hydroxylation of ecdysone to the steroid insect molting hormone 20-hydroxyecdysone. Proc Natl Acad Sci USA 100: 13773-13778.

PHILIPS, J.A., RUBIN, E.J. and PERRIMON, N. (2005). Drosophila RNAi screen reveals CD36 family member required for mycobacterial infection. Science 309: 1251-1253.
PUSSINEN, P.J., KARTEN, B., WINTERSPERGER, A., REICHER, H., MCLEAN, M., MALLE, E. and SATTLER, W. (2000). The human breast carcinoma cell line HBL-100 acquires exogenous cholesterol from high-density lipoprotein via CLA1 (CD-36 and LIMPII analogous 1)-mediated selective cholesteryl ester uptake. Biochem J 349: 559-566.

REAVEN, E., BOYLES, J., SPICHER, M. and AZHAR, S. (1988). Evidence for surface entrapment of cholesterol-rich lipoproteins in luteinized ovary. Arteriosclerosis 8: 298-309.

REAVEN, E., CHEN, Y.D., SPICHER, M. and AZHAR, S. (1984). Morphological evidence that high density lipoproteins are not internalized by steroid-producing cells during in situ organ perfusion. J Clin Invest 74: 1384-1397.

REAVEN, E., CHEN, Y.D., SPICHER, M., HWANG, S.F., MONDON, C.E. and AZHAR, S. (1986). Uptake of low density lipoproteins by rat tissues. Special emphasis on the luteinized ovary. J Clin Invest 77: 1971-1984.

REAVEN, E., LEERS-SUCHETA, S., NOMOTO, A. and AZHAR, S. (2001). Expression of scavenger receptor class $B$ type 1 (SR-BI) promotes microvillar channel formation and selective cholesteryl ester transport in a heterologous reconstituted system. Proc Natl Acad Sci USA 98: 1613-1618.

REAVEN, E., SHI, X.Y. and AZHAR, S. (1990). Interaction of lipoproteins with isolated ovary plasma membranes. J Biol Chem 265: 19100-19111.

REAVEN, E., SPICHER, M. and AZHAR, S. (1989). Microvillar channels: a unique plasma membrane compartment for concentrating lipoproteins on the surface of rat adrenal cortical cells. J Lipid Res 30: 1551-1560.

RIGOTTI, A., ACTON, S.L. and KRIEGER, M. (1995). The class B scavenger receptors SR-BI and CD36 are receptors for anionic phospholipids. J Biol Chem 270: $16221-16224$

RIZKI, M.T.M. (1956). The cytophysiology of the spiracular glands of Drosophila Melanogaster. J. Morphology 98: 497-511.

ROMAÑÁ, I., PASCUAL, N. and BELLÉS, X. (1995). The ovary is a source of circulating ecdysteroids in Blatella germanica (Dictyoptera: Blattellidae). Eur. J. Entomology 92: 93-103.

ROXSTROM-LINDQUIST, K., TERENIUS, O. and FAYE, I. (2004). Parasite-specific immune response in adult Drosophila Melanogaster. a genomic study. EMBO Rep 5: 207-212.

RYEOM, S.W., SPARROW, J.R. and SILVERSTEIN, R.L. (1996). CD36 participates in the phagocytosis of rod outer segments by retinal pigment epithelium. J Cell Sci 109 (Pt 2): 387-395.

SEARS, H.C., KENNEDY, C.J. and GARRITY, P.A. (2003). Macrophage-mediated corpse engulfment is required for normal Drosophila CNS morphogenesis. Development 130: 3557-3565.

STUART, L.M., DENG, J., SILVER, J.M., TAKAHASHI, K., TSENG, A.A., HENNESSY, E.J., EZEKOWITZ, R.A. and MOORE, K.J. (2005). Response to Staphylococcus aureus requires $\mathrm{CD} 36$-mediated phagocytosis triggered by the $\mathrm{COOH}$-terminal cytoplasmic domain. J Cell Biol 170: 477-485.

THOMPSON, M.J., SVOBODA, J.A. and WEIRICH, G.F. (1984). Ecdysteroids in developing ovaries and eggs of the tobacco hornworm. Steroids 43: 333-341.

VEGA, M.A., SEGUI-REAL, B., GARCIA, J.A., CALES, C., RODRIGUEZ, F., VANDERKERCKHOVE, J. and SANDOVAL, I.V. (1991). Cloning, sequencing, and expression of a cDNA encoding rat LIMP II, a novel 74-kDa lysosomal membrane protein related to the surface adhesion protein CD36. J Biol Chem 266: 16818-16824.

VOOLSTRA, O., KIEFER, C., HOEHNE, M., WELSCH, R., VOGT, K. and VON LINTIG, J. (2006). The Drosophila class B scavenger receptor NinaD-I is a cell surface receptor mediating carotenoid transport for visual chromophore synthesis. Biochemistry 45: 13429-13437.

WANG, T., JIAO, Y. and MONTELL, C. (2007). Dissection of the pathway required for generation of vitamin A and for Drosophila phototransduction. J Cell Biol 177: 305-316

WILLIAMS, D.L., WONG, J.S. and HAMILTON, R.L. (2002). SR-BI is required for microvillar channel formation and the localization of HDL particles to the surface of adrenocortical cells in vivo. J Lipid Res 43: 544-549.

YANG, J. and O'TOUSA, J.E. (2007). Cellular sites of Drosophila NinaB and NinaD activity in vitamin A metabolism. Mol Cell Neurosci 35: 49-56.

YE, Y.H., CHENOWETH, S.F. and MCGRAW, E.A. (2009). Effective but costly, evolved mechanisms of defense against a virulent opportunistic pathogen in Drosophila Melanogaster. PLoS Pathog 5: e1000385. 


\section{Further Related Reading, published previously in the Int. J. Dev. Biol.}

Ecdysone signaling is required for proper organization and fluid secretion of stellate cells in the Malpighian tubules of Drosophila melanogaster

Naveen-Kumar Gautam and Madhu G. Tapadia

Int. J. Dev. Biol. (2010) 54: 635-642

Ventral nerve cord remodeling in a stingless bee (Melipona quadrifasciata anthidioides, Hymenoptera, A pidae) depends on ecdysteroid fluctuation and programmed cell death Lucimara Z Pinto, Marcela A F B Laure, Márcia M G Bitondi, Klaus Hartfelder and Zilá L P Simões

Int. J. Dev. Biol. (2003) 47: 385-388

On the hormonal control of insect metamorphosis. A historical review P Karlson

Int. J. Dev. Biol. (1996) 40: 93-96

The brain secretory peptides that control moulting and metamorphosis of the silkmoth, Bombyx mori

$\mathrm{H}$ Ishizaki and A Suzuki

Int. J. Dev. Biol. (1994) 38: 301-310

Cuticle secretion in Drosophila wing imaginal discs in vitro: parameters of exposure to 20-hydroxy ecdysone

$\mathrm{S}$ A Johnson and M J Milner

Int. J. Dev. Biol. (1990) 34: 299-307

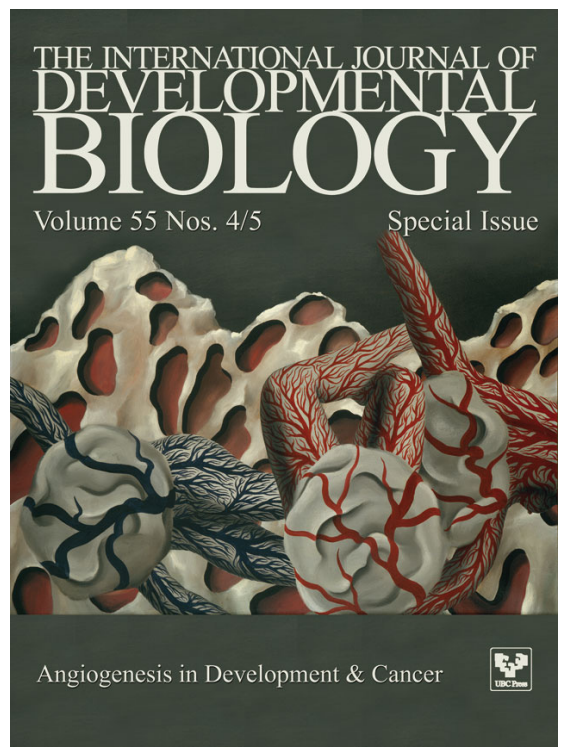

ISI Impact Factor $(\mathbf{2 0 1 0})=\mathbf{2 . 8 6}$

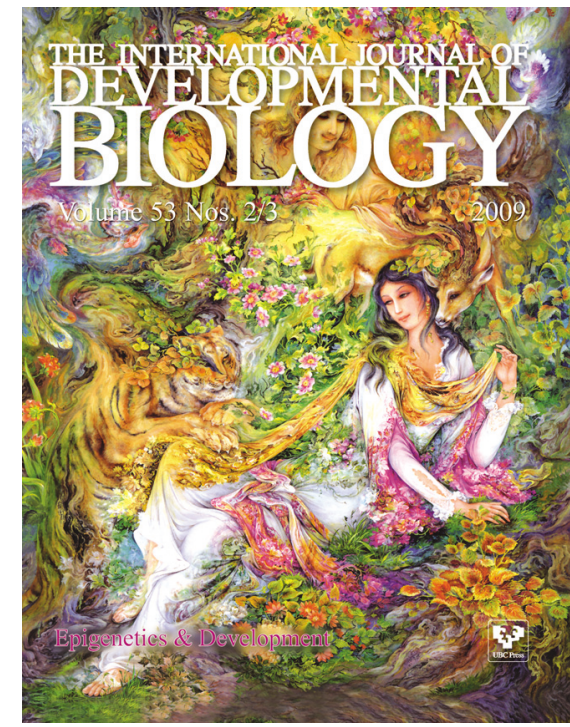

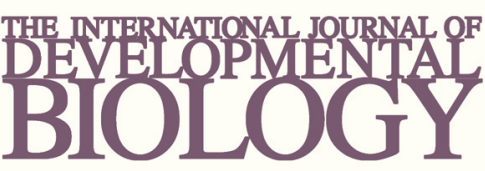

Volume 54 Nos. $6 / 7$
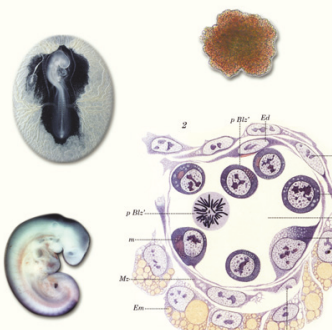

Special Issue
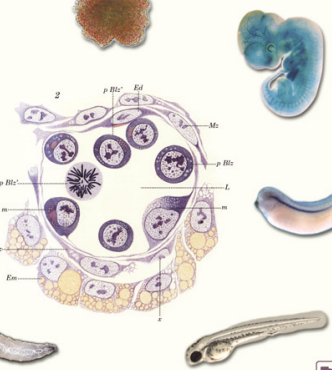

Developmental Hematopoiesis

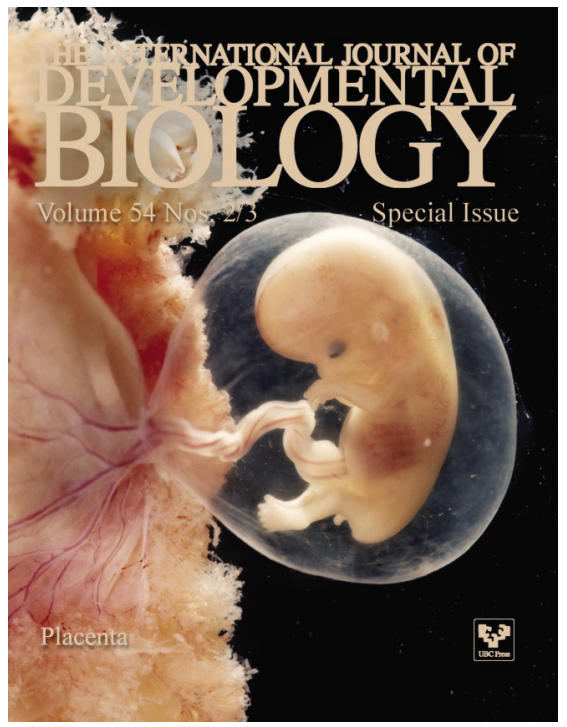

